\title{
Heterologous synthesis of chlorophyll $b$ in Nannochloropsis salina enhances growth and lipid production by increasing photosynthetic efficiency
}

\author{
Hyun Gi Koh ${ }^{1,2}$, Nam Kyu Kang ${ }^{1,3}$, Seungjib Jeon², Sung-Eun Shin ${ }^{2,4}$, Byeong-ryool Jeong ${ }^{2 *}$ (i) \\ and Yong Keun Chang ${ }^{1,2^{*}}$
}

\begin{abstract}
Background: Chlorophylls play important roles in photosynthesis, and thus are critical for growth and related metabolic pathways in photosynthetic organisms. They are particularly important in microalgae, emerging as the next generation feedstock for biomass and biofuels. Nannochloropsis are industrial microalgae for these purposes, but are peculiar in that they lack accessory chlorophylls. In addition, the localization of heterologous proteins to the chloroplast of Nannochloropsis has not been fully studied, due to the secondary plastid surrounded by four membranes. This study addressed questions of correct localization and functional benefits of heterologous expression of chlorophyllide a oxygenase from Chlamydomonas (CrCAO) in Nannochloropsis.

Results: We cloned CrCAO from Chlamydomonas, which catalyzes oxidation of Chla producing Chlb, and overexpressed it in N. salina to reveal effects of the heterologous Chlb for photosynthesis, growth, and lipid production. For correct localization of CrCAO into the secondary plastid in N. salina, we added the signal-recognition sequence and the transit peptide (cloned from an endogenous chloroplast-localized protein) to the $\mathrm{N}$ terminus of $\mathrm{CrCAO}$. We obtained two transformants that expressed $\mathrm{CrCAO}$ and produced $\mathrm{Chl} b$. They showed improved growth under medium light $\left(90 \mu \mathrm{mol} / \mathrm{m}^{2} / \mathrm{s}\right)$ conditions, and their photosynthetic efficiency was increased compared to WT. They also showed increased expression of certain photosynthetic proteins, accompanied by an increased maximum electron-transfer rate up to $15.8 \%$ and quantum yields up to 17\%, likely supporting the faster growth. This improved growth resulted in increased biomass production, and more importantly lipid productivity particularly with medium light.

Conclusions: We demonstrated beneficial effects of heterologous expression of CrCAO in Chlb-less organism N. salina, where the newly produced Chlb enhanced photosynthesis and growth. Accordingly, transformants showed improved production of biomass and lipids, important traits of microalgae from the industrial perspectives. Our transformants are the first Nannochloropsis cells that produced Chlb in the whole evolutionary path. We also succeeded in delivering a heterologous protein into the secondary plastid for the first time in Nannochloropsis. Taken together, our data showed that manipulation of photosynthetic pigments, including Chlb, can be employed in genetic improvements of microalgae for production of biofuels and other biomaterials.
\end{abstract}

Keywords: Microalgae, Nannochloropsis salina, Chlorophyll b, Chlorophyllide a oxygenase (CAO), Biofuels, Photosynthesis

\footnotetext{
*Correspondence: bjeong@kaist.ac.kr; ychang@kaist.ac.kr

${ }^{2}$ Department of Chemical and Biomolecular Engineering, KAIST,

291 Daehak-ro, Yuseong-gu, Daejeon 34141, Republic of Korea

Full list of author information is available at the end of the article
} 


\section{Background}

Chlorophylls are photosynthetic pigments that play important roles in oxygenic photosynthesis in cyanobacteria, algae, and plants. Photosynthesis harnesses the sun's energy to produce oxygen and to fix carbons, which provide basic necessities for all life on Earth. In particular, photosynthesis in microalgae is emerging as valuable sources for the next-generation biomass and biofuels. Improving microalgal photosynthesis is thus critical for successful production of sustainable biomaterials, and understanding functions of chlorophylls is one of the keys to successful employment of microalgae. In fact, engineering of photosynthesis is being actively pursued to improve production of biomass in crops and microalgae [1].

Chlorophylls (Chls) are magnesium-tetrapyrrole molecules, and have functions in harvesting light energy in the light-harvesting complexes (LHCs) and in driving chargeseparation reactions in the reaction centers [2]. Chlorophylls are evolutionarily conserved, and are used as taxonomic keys for photosynthetic organisms [3]. Chlorophyll $a(\mathrm{Chl} a)$ is the universal photosynthetic pigment that is present in most oxygenic photosynthetic organisms, and performs all of the above functions [4]. Chl $b$ and other accessory pigments are mainly involved in light harvesting in LHCs, and are expected to improve lightharvesting efficiency $[2,5,6]$. Chlc is another accessory pigment involved in light harvesting, and is found in heterokont algae descended from secondary endosymbiosis [7]. Heterokonts are polyphyletic and are represented by diatoms and Nannochloropsis; however, Nannochloropsis have lost $\mathrm{Chl} c$, and carotenoids have taken over the functions of accessory pigments $[8,9]$.

Lack of accessory chlorophylls in Nannochloropsis is interesting in that they have been known for robust growth and lipid production. In fact, Nannochloropsis are considered model microalgae with remarkable potential for industrial production of biomass and lipids [10-13]. However, their photosynthetic efficiency has been in question due to the lack of pyrenoids that serve as a carbon concentration mechanism in many microalgae, even though alternative mechanism(s) may exist [12, 14, 15]. Accessory chlorophylls are known to improve photosynthesis in part by extending the light absorption spectrum and antennal assembly, which can also affect growth and hormonal responses $[2,5]$. It would be interesting to test if an accessory chlorophyll would be beneficial for photosynthesis in Nannochloropsis. Currently, genetic information about $\mathrm{Chl} c$ biosynthesis is unknown $[7,16]$; however, $\mathrm{Chl} b$ is produced simply by successive hydroxylations of chlorophyllide $a$ or Chla, catalyzed by a single enzyme called chlorophyllide $a$ oxygenase (CAO) in Chlamydomonas $[2,17,18]$, opening the possibility to produce
Chlb in Nannochloropsis. Considering the reports of remarkable increase in starch contents and growth rate after overproduction of Chlb [19] in Nicotiana tabacum, there is a possibility of positive effect by heterologous synthesis of Chlb in N. salina as well. We expressed the catalytic domain of CAO from Chlamydomonas in $N$. salina CCMP 1776 to determine if $\mathrm{Chl} b$ produced by the heterologous CAO had beneficial effects on growth and photosynthesis. CAOs contain three domains, called $\mathrm{A}, \mathrm{B}$, and $\mathrm{C}$ domains, in Chlamydomonas and plants, among which the $\mathrm{C}$ domain is catalytic, while the $\mathrm{A}$ and $B$ domains are regulatory $[17,20]$. Interestingly, the $\mathrm{A}$ and $\mathrm{B}$ domains are missing in other microalgae and cyanobacterium Prochlorothrix hollandica, and the $\mathrm{C}$ domain is sufficient for biochemical functions of $\mathrm{CAO}$ $[17,21,22]$. For proper delivery of CAO into the chloroplast endoplasmic reticulum (cER) and the chloroplast in Nannochloropsis, we added signal and transit peptide sequences from a chloroplast-localized protein Glycine Cleavage System L protein (GCSL, encoding dihydrolipoamide dehydrogenase) in Nannochloropsis at the $\mathrm{N}$ terminus of CAO. cER originated from the secondary symbiosis of a red algal ancestor, which is a characteristic of heterokonts [14, 23], and localization requires the signal peptide prior to the chloroplast localization [24, 25], as summarized in Fig. 1a.

Expression of the recombinant CAO in Nannochloropsis resulted in the production of $\mathrm{Chl} b$ with improved photosynthesis and growth, and most importantly, with the increased lipid productivity. Improved photosynthesis by $\mathrm{CAO}$ is consistent with the previous findings that $\mathrm{Chl} b$ is also involved in antennal assembly and optogenetic signaling in plants and Chlamydomonas $[5,6,26]$. We also show that the improvements were further enhanced under low light conditions, suggesting that production of Chl $b$ contributed to more efficient light harvesting. To our best knowledge, this is the first study to produce the accessory Chl $b$ in heterokonts and to express heterologous protein in cER in Nannochloropsis by adding the signal and transit peptide sequences. Conclusively, this report provides an excellent proof of concept that simple introduction of CAO into industrial heterokonts could improve production of biomass and lipids.

\section{Results}

\section{Construction of CAO expression vector (pNsChlb)} and transformation into N. salina CCMP 1776

We cloned the catalytic domain of the $C A O$ gene from Chlamydomonas reinhardtii CC-124 (CrCAO; GenBank accession: XM_001690123.1) via RT-PCR and inserted it downstream of the TUB promoter, resulting in the pNsChlb vector (Fig. 1b). To ensure proper localization to the chloroplast, we fused the signal peptide and 


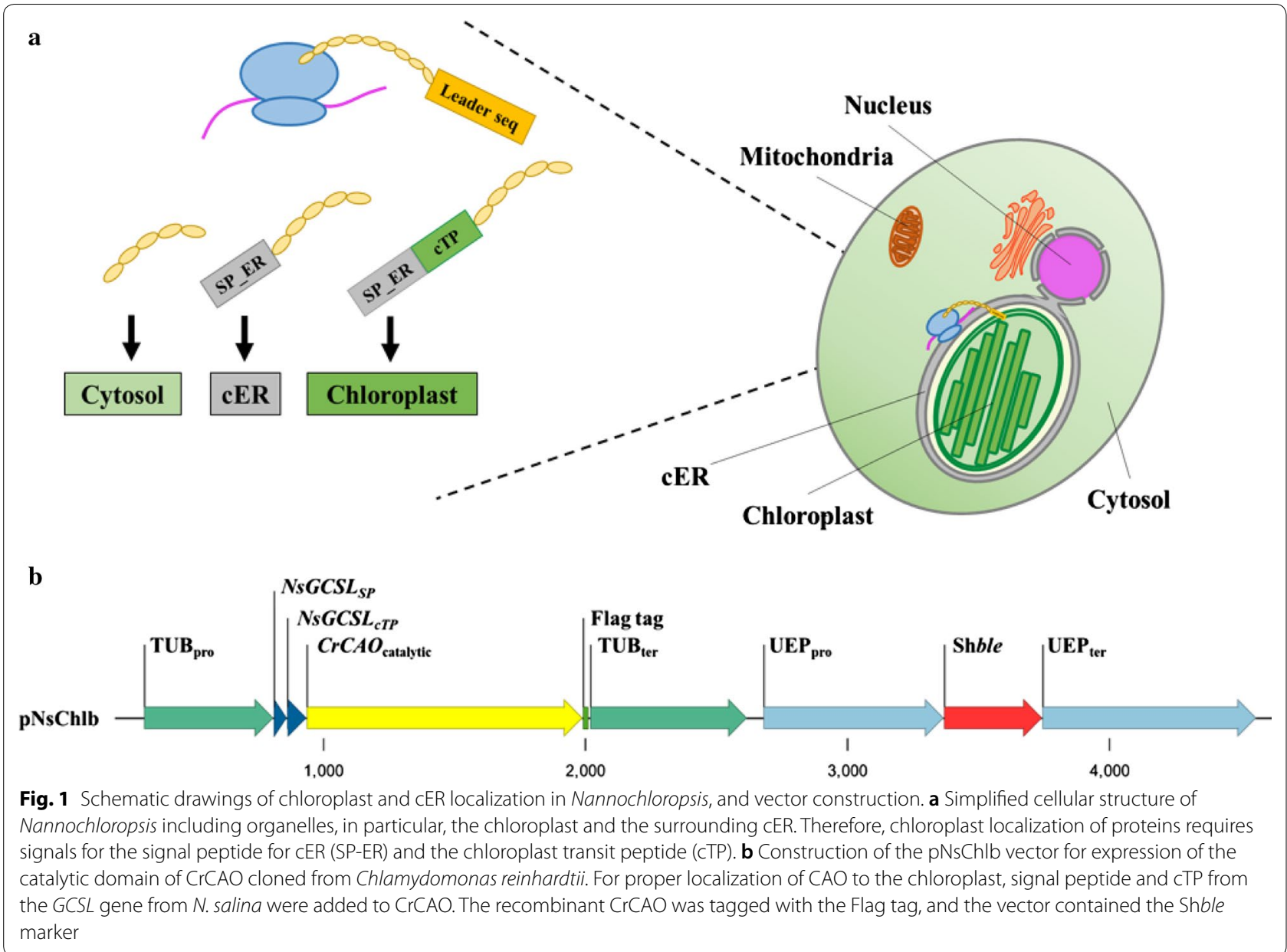

chloroplast transit peptide (cTP) from a chloroplastlocalized protein GCSL (Additional file 1: Figure S1) at the $\mathrm{N}$ terminus of $\mathrm{CrCAO}$. The GCSL sequence was initially found in the genome of N. gaditana (Genbank accession: Naga_100001g181) via the Nannochloropsis Genome Portal (http://www.nannochloropsis.org/) [27], and was amplified from the cDNA of $N$. salina CCMP1776 using primers GC1 and GC2 (Additional file 2: Table S1). The signal peptide and transit peptide of GCSL were confirmed by SignalP 4.1 [28], ChloroP [29], and HECTAR [30] (Additional file 3: Figure S2). The chimeric $\mathrm{CrCAO}$ was tagged with 'Flag' at the $\mathrm{C}$ terminus for western detection, and the vector contained the Shble marker gene that allowed selection of transformants with an antibiotic Zeocin.

Transformants were selected on F2 N agar plates containing $2.5 \mu \mathrm{g} / \mathrm{mL}$ of Zeocin after electroporation, and we confirmed the presence of the vector sequence via genomic PCR (Fig. 2a) and the expression of CrCAO::Flag via western blot for Flag (Fig. 2b). Integration of the vector was confirmed by RESDA-PCR (restriction enzyme site-directed amplification-polymerase chain reaction), revealing integration at the UTR of a hypothetical gene (homolog of Naga_101464g1.1 in N. gaditana B-31) in NsChlb7 and in an intergenic region near a gene (homologous to Naga_100033g27 in N. gaditana B-31 encoding phosphatase 2C) in NsChlb19, which do not appear to affect phenotypes of transformants (Additional file 4: Figure S3). The chimeric CrCAO was detectable only in transformants NsChlb 7 and NsChlb 19 at $39.5 \mathrm{kDa}$. It should be noted that this size is expected for the processed protein in the chloroplast, instead of the full length $(43.88 \mathrm{kDa})$, suggesting successful removal of the signal and transit peptide sequences during translocation to the chloroplast. Actual localization of the produced CrCAO proteins are further confirmed by immuno-gold labeling technique with transmission electron microscopy (Additional file 5: Figure S4).

Production of $\mathrm{Chl} b$ was analyzed with high-performance liquid chromatography (HPLC), as shown in Fig. 2c. Chl $a$ and other photosynthetic pigments were well represented in all samples, while the peak for Chlb 

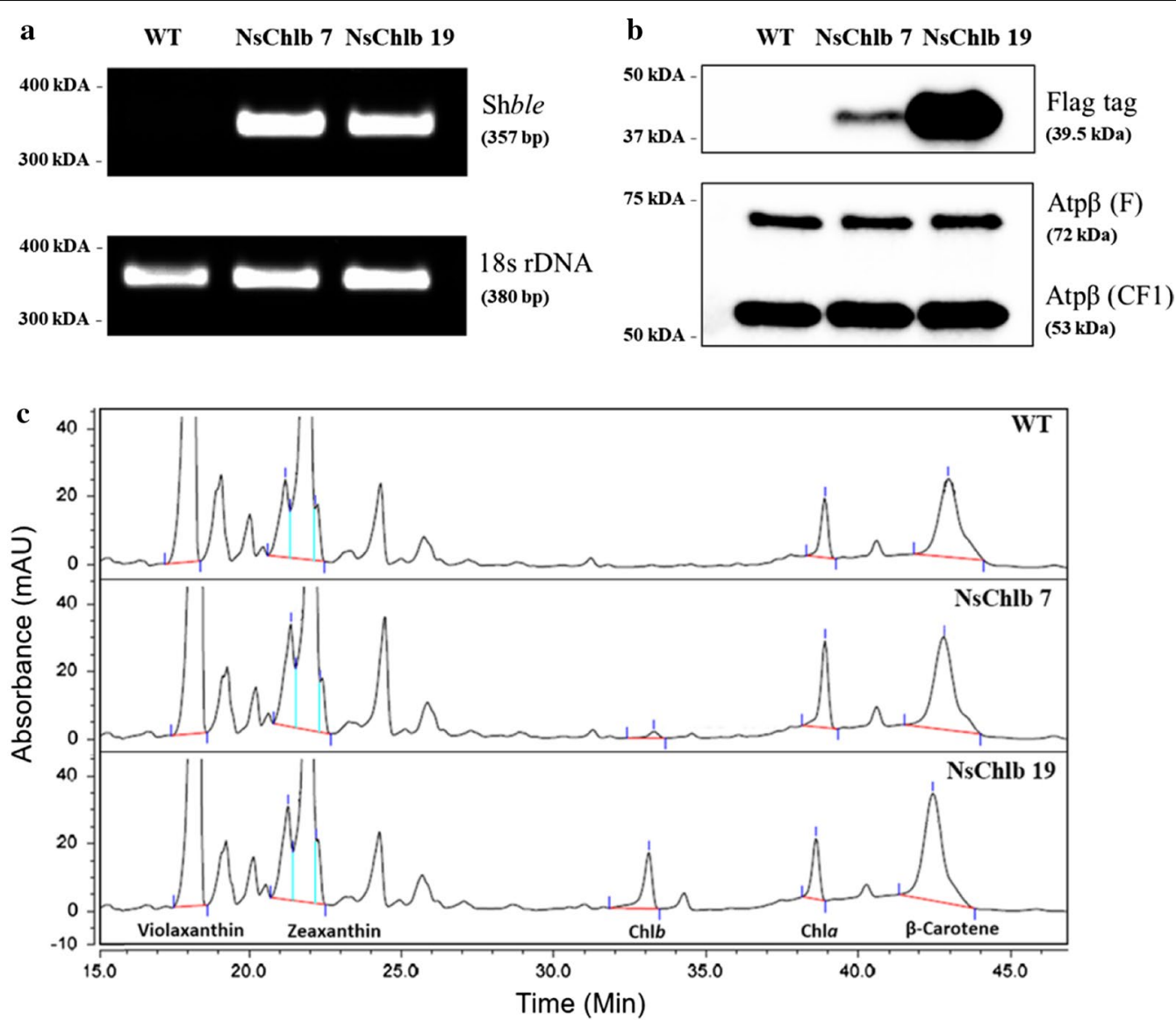

Fig. 2 Characterization of transformants of CrCAO. a PCR detection of the inserted plasmid (pNsChlb) by amplifying the 375 bp Shble sequence only in transformants NsChlb7 and NsChlb19. The 380 bp product of 185 rDNA was used as a loading control and was detected in all samples. b Western blotting for expression of the FLAG-tagged CrCAO protein from transformants. The Flag tag was detected only in transformants, while the $\beta$ subunit of ATP synthase (Atp $\beta$ ) appeared as the F-type H-ATPase $\beta$ subunit $(72.6 \mathrm{kDa}$ ) and the CF1 $\beta$ subunit ( $53.13 \mathrm{kDa}$ ) in WT and transformants. c Detection of chlorophylls and other photosynthetic pigments via HPLC at $460 \mathrm{~nm}$ absorbance. Peaks for chlorophyll $a$ and a few carotenoids including $\beta$-carotene and violaxanthin were shown. Emergence of chlorophyll $b$ was detected only in the transformants

was only detectable in transformants. Interestingly, NsChlb 19 showed more accumulation of Chl $b$ than $\mathrm{NsChlb} \mathrm{7,} \mathrm{consistent} \mathrm{with} \mathrm{higher} \mathrm{expression} \mathrm{of} \mathrm{CrCAO}$ protein, as shown Fig. 2b. These two transformants, NsChlb 7 and NsChlb 19, were used for further analyses.

Effects of CrCAO on growth under different light intensities We analyzed the growths of WT, NsChlb7, and NsChlb 19 under high (HL: $200 \mu \mathrm{mol}$ photons $/ \mathrm{m}^{2} / \mathrm{s}$ ) and medium light intensities (ML: $90 \mu \mathrm{mol}$ photons $/ \mathrm{m}^{2} / \mathrm{s}$ ) to reveal beneficial effects of $\mathrm{Chl} b$ on growth under different light conditions (Fig. 3). Growths estimated by cell density (Fig. 3a) and dried cell weight (DCW; Fig. 3b) showed improvements in transformants under medium light in NsChlb19, particularly during the later phase of growth (days 10-12). The cell number on day 12 was $18-26 \%$ higher in transformants compared to that of the WT with ML, with a concomitant increase in DCW of 29-31\%, where NsChlb7 showed similar improvements but no significance. However, there were no significant differences in growth for the transformants under HL (Fig. 3c, d), suggesting that the extra $\mathrm{Chl} b$ contributed to growth under ML.

\section{Photosynthetic parameters and pigments}

We further analyzed photosynthetic efficiency and pigments that may be contributed by the novel production of Chl $b$, as summarized in Fig. 4 and Table 1. Cells were cultured with $\mathrm{ML}$ and $\mathrm{HL}$, and were subjected to photometric measurement of photosynthesis using Multi-color-PAM. The maximum quantum yield of photosystem II $(\mathrm{Fv} / \mathrm{Fm})$ was in the range of $0.62 \pm 0.02$ in all strains and did not show differences between WT and transformants (Fig. 4a, b), in agreement with the relatively constant maximum quantum yield in other photosynthetic organisms under no environmental stresses 

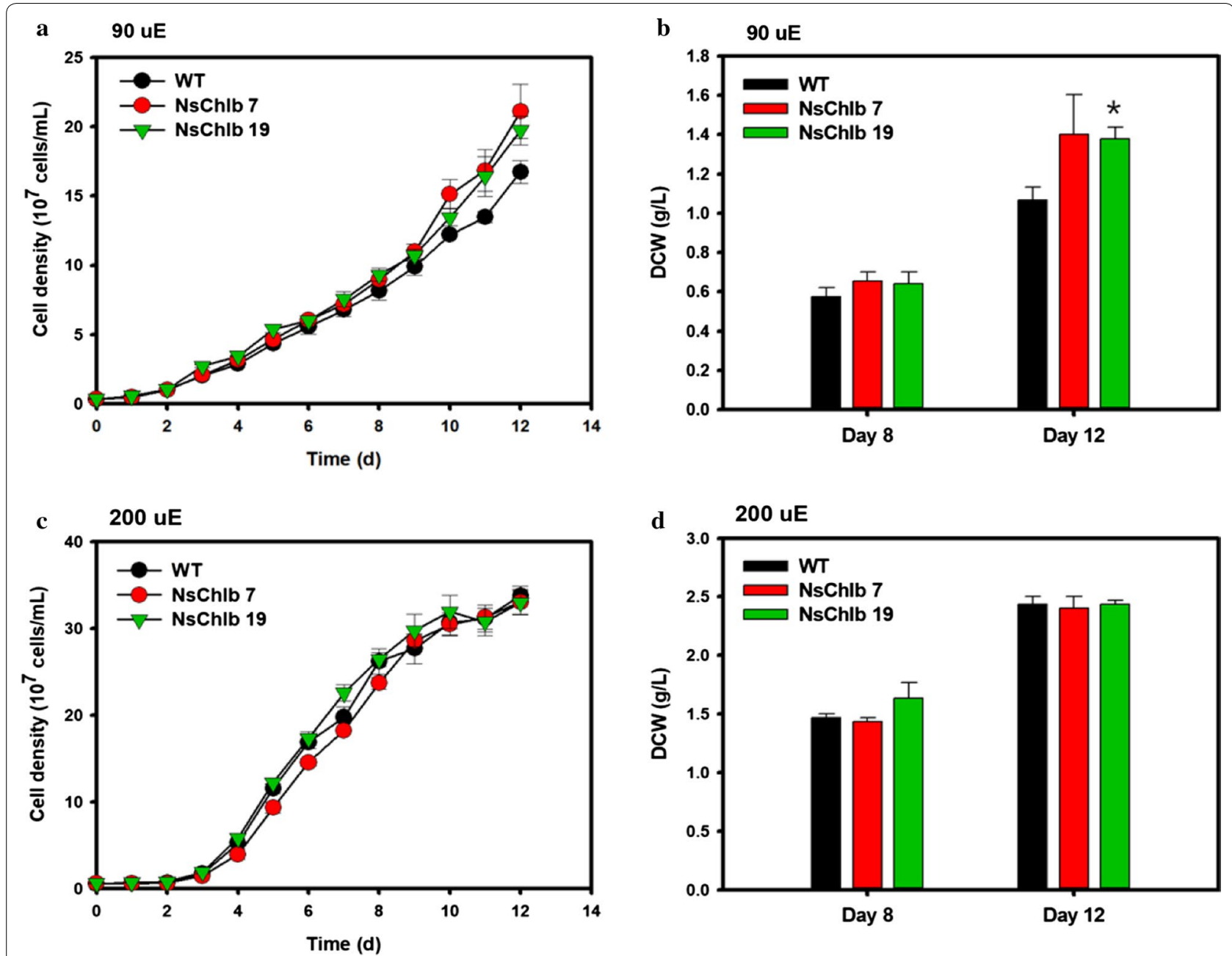

Fig. 3 Growth analyses of Chlb synthesizing transformants under different light intensities of medium light (ML: 90 mmol photons $/ \mathrm{m}^{2} / \mathrm{s}$ ) and high light (HL: $200 \mu \mathrm{mol}$ photons $/ \mathrm{m}^{2} / \mathrm{s}$ ). The cell density $(\mathbf{a}, \mathbf{c})$ and dry cell weight (DCW: b, d) were analyzed under $\mathrm{ML}(\mathbf{a}, \mathbf{b})$ and HL $(\mathbf{c}, \mathbf{d})$. Data points represent means and standard errors $(n=3)$. Asterisks indicate the significant differences between WT and each transformants (WT vs. NsChlb7, WT vs. NsChlb19) determined by Student's $t$ test $\left({ }^{*} P<0.05,{ }^{* *} P<0.01,{ }^{* * *} P<0.001\right)$

[31]. However, transformants showed moderate but significant improvements in quantum yield measured with higher light intensities, particularly in NsChlb 19, which expressed more CAO proteins (inlets in Fig. 4a, b). Transformants also showed improved electron transfer rates compared to WT (Fig. 4c, d). We also measured the yield of non-photochemical quenching (NPQ) for heat dissipation of light energy received through the light-harvesting complex (LHC), but did not find any significant differences in samples (Fig. 4e, f). Overall, transformants showed improved quantum yield and electron transport, and a moderate reduction in NPQ, which could contribute to improved growth under ML.

We also measured chlorophyll and carotenoid contents in greater detail, after cultivation for 8 and 12 days
(Table 1). Likely through the catalytic activity of heterologous $\mathrm{CrCAO}, \mathrm{Chl} b$ was detectable only in transformants NsChlb 7 and NsChlb 19, which was also shown in the HPLC profile (Fig. 2c). As described earlier, NsChlb 19 expressed more $\mathrm{CrCAO}$ and produced more Chlb. Chla showed a tendency of increasing content on day 8 under ML, especially in NsChlb7 strain. However, no significant changes were observed in other conditions in both transformants. Chl $a$ is converted to Chl $b$; however, we did not observe decreased Chla content in transformants in any cases, likely because only a small fraction of Chla was converted to Chl $b$. Overall, chlorophyll contents decreased under HL compared to ML, probably due to antennal reduction under HL [32]. In addition to chlorophylls, we also measured carotenoids including 

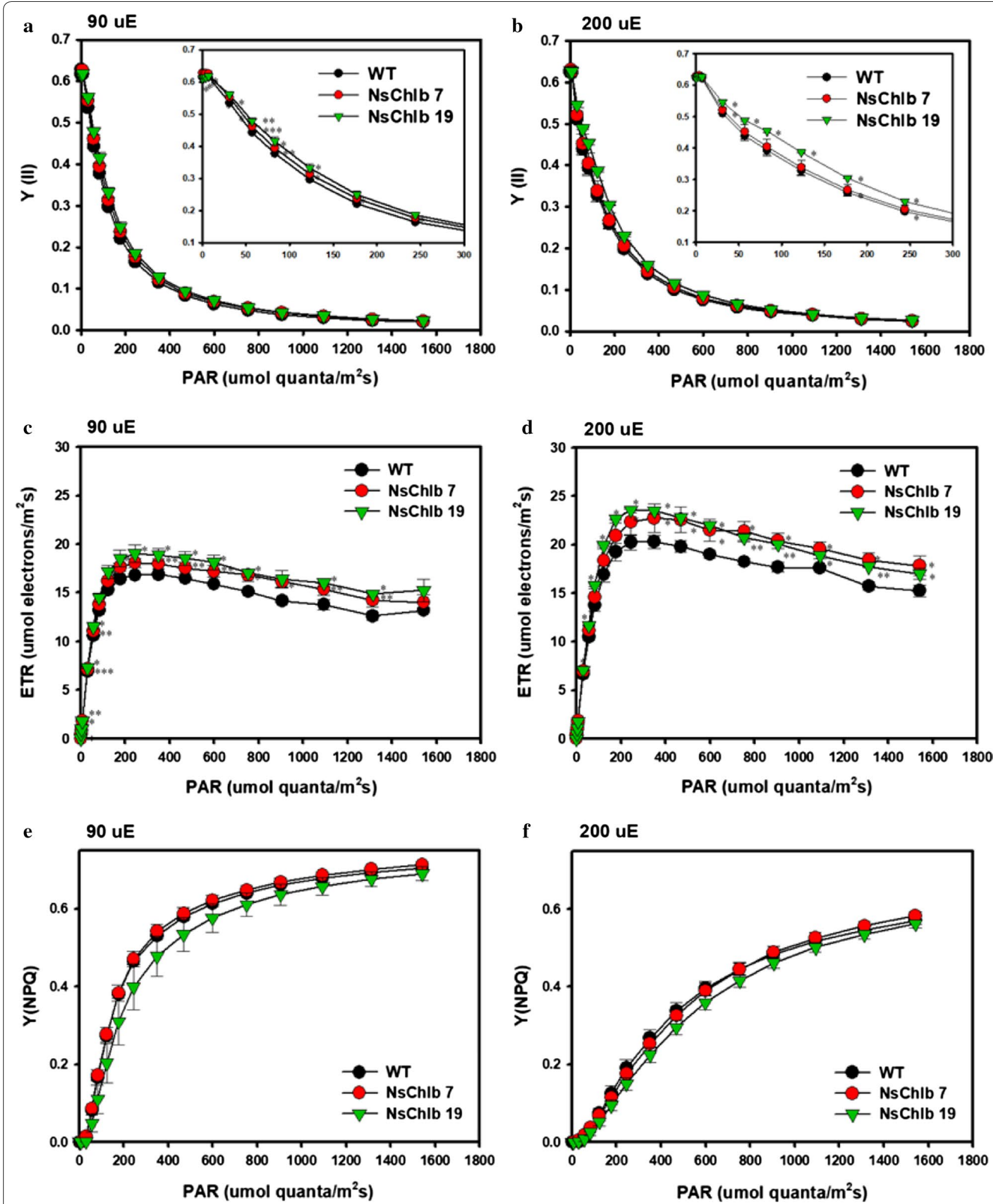

Fig. 4 Comparison of photosynthetic parameters in WT and transformants employing Pulse-Amplitude-Modulation (PAM) fluorometry using cells grown under ML (90 uE) and $\mathrm{HL}(200 \mathrm{uE})$. The quantum yields at the increasing light intensity of strains cultivated under ML (a) and HL (b). Insets show close-up values of measurements with light intensity of $<300 \mu \mathrm{E}$. The electron-transfer rates (ETRs) with the increasing light intensity under $\mathrm{ML}$ (c) and $\mathrm{HL}(\mathbf{d})$. Changes in non-photo chemical quenching (NPQ) yield with the increasing light intensity under ML (e) and HL (f). Data points represent means and standard errors $(n=3)$. Asterisks indicate the significant differences between WT and each transformants (WT vs. NsChlb7, WT vs. NsChlb19) determined by Student's $t$ test $\left({ }^{*} P<0.05,{ }^{* *} P<0.01,{ }^{* * *} P<0.001\right)$ 
Table 1 Photosynthetic pigments analyzed by HPLC

\begin{tabular}{|c|c|c|c|c|c|c|c|}
\hline \multirow[t]{2}{*}{ (Scale: $\mu \mathrm{g} / \mathrm{mg}$ ) } & \multirow[t]{2}{*}{ Pigments } & \multicolumn{3}{|l|}{$\mathrm{ML}(90 \mu \mathrm{E})$} & \multicolumn{3}{|l|}{$\mathrm{HL}(200 \mu \mathrm{E})$} \\
\hline & & WT & NsChlb 7 & NsChlb 19 & WT & NsChlb 7 & NsChlb 19 \\
\hline \multirow[t]{5}{*}{ Day 8} & Chla & $45.36 \pm 3.13$ & $57.61 \pm 1.69^{*}$ & $50.09 \pm 1.09$ & $43.92 \pm 3.42$ & $50.70 \pm 2.30$ & $39.48 \pm 2.44$ \\
\hline & Chlb & n.d. & $0.28 \pm 0.05$ & $1.51 \pm 0.13$ & n.d. & $0.18+0.01$ & $0.53+0.07$ \\
\hline & Violaxanthin & $3.88 \pm 0.06$ & $4.48 \pm 0.09$ & $4.04 \pm 0.17$ & $4.10 \pm 0.29$ & $5.06 \pm 0.26^{*}$ & $3.90 \pm 0.21$ \\
\hline & $\beta$-carotene & $4.42 \pm 0.45$ & $4.07 \pm 0.83$ & $4.58 \pm 0.93$ & $1.08 \pm 0.42$ & $2.36 \pm 0.06^{* *}$ & $1.85 \pm 0.07^{*}$ \\
\hline & Zeaxanthin & $0.09 \pm 0.01$ & $0.12 \pm 0.01$ & $0.16 \pm 0.01$ & $0.10 \pm 0.01$ & $0.11 \pm 0.01$ & $0.10 \pm 0.01$ \\
\hline \multirow[t]{5}{*}{ Day 12} & Chla & $72.52 \pm 1.90$ & $75.86 \pm 8.84$ & $70.55 \pm 4.43$ & $23.25 \pm 1.30$ & $25.86 \pm 1.16$ & $20.23 \pm 1.30$ \\
\hline & Chlb & n.d. & $0.15 \pm 0.07$ & $0.97 \pm 0.40$ & n.d. & $0.05 \pm 0.02$ & $0.13 \pm 0.05$ \\
\hline & Violaxanthin & $7.37 \pm 0.08$ & $7.52 \pm 1.22$ & $7.42 \pm 0.29$ & $1.81 \pm 0.19$ & $2.10 \pm 0.23$ & $1.70 \pm 0.17$ \\
\hline & $\beta$-carotene & $5.68 \pm 0.09$ & $5.84 \pm 0.55$ & $5.49 \pm 0.19$ & $1.39 \pm 0.10$ & $1.67 \pm 0.17$ & $1.34 \pm 0.02$ \\
\hline & Zeaxanthin & $0.12 \pm 0.01$ & $0.11 \pm 0.01$ & $0.09 \pm 0.20$ & $0.17 \pm 0.01$ & $0.20 \pm 0.03$ & 0.13 \\
\hline
\end{tabular}

The data represent the average value with ranges of standard error $(n=3)$. Significant differences between WT and each transformants (WT vs. NsChlb7, WT vs. $\mathrm{NsChlb19)}$ are determined by Student's $t$ test and are indicated by asterisks $\left({ }^{*} P<0.05,{ }^{* *} P<0.01,{ }^{* * *} P<0.001\right)$

Violaxanthin, $\beta$-carotene, and zeaxanthin. Transformants did not show substantial and/or consistent changes in carotenoid content compared to WT. Taken together, the results indicate that chlorophylls (particularly Chl $b$ ) may have contributed to the improved photosynthesis in CrCAO transformants.

\section{Quantitation of antenna and other photosynthetic proteins}

For further understanding of the photosynthetic improvements in Chl b-producing transformants, we quantitated antenna and other photosynthetic proteins via western blot followed by quantitation of band intensity using Chemi-Doc (Fig. 5). The ATP $\beta$ subunit was used as a loading control to normalize the intensity of blotted bands. We did not find any difference in cytochrome $\mathrm{f}$ in transformants compared to WT, but found a slight decrease in photosystem I (PSI) components, even though no proteins showed significant differences. However, we observed general trends of increasing LHCII antennal components (Lhcb1-like, Lhcb2-like, Lhcb3-like, and Lhcb4-like proteins), except for Lhcb1 in NsChlb 7 under ML, which might have contributed to increased photosynthesis. For the analysis of the LHCII antennal components, we used each antibody targeting Lhcb1 $\sim$ proteins (Agrisera, USA) in C. reinhardtii, as antibodies targeting LHCII proteins in heterokonts are not widely available. Interestingly, Lhcb4-like protein was greatly increased in transformants under ML, albeit with large error bars, which may reflect its accumulation pattern depending on light intensity and/or chlorophyll content in microalgae and plants [5, 33, 34]. PSII core proteins (D1 and D2) were reduced or did not change in transformants under ML, but increased under HL, which may be correlated with stabilizing effect of $\mathrm{Chl} b$ under light intensive conditions [35]. Overall, we showed that $\mathrm{Chl} b$ production was associated with enhanced accumulation of LHCII and PSII core proteins, which may contribute to enhanced photosynthesis in $\mathrm{CrCAO}$ transformants.

\section{Assessment of lipid production in CrCAO transformants}

Lipid production in CrCAO transformants was also analyzed, since they showed improvements in photosynthetic efficiency and growth. We used high performance liquid chromatography (HPLC) to quantitate different types of lipids under ML and HL conditions, and showed lipid contents (Table 2) and lipid productivities (Fig. 6). Overall, TAG contents were not changed substantially, although NsChlb 7 showed a slight but significant decrease in TAG content under ML on day 12. Under HL, transformants showed a tendency of increased TAG content on day 8 , which may be correlated to their increased photosynthesis (Fig. 4b, d) without change in growth (Fig. 3c, d). MAG was not detectable on day 8 with ML, but accumulated on day 12, while it was detectable under HL. We did not found any significant changes in MAG content in any samples. Galactolipids, including monogalactosyldiacylglycerol (MGDG) and digalactosyldiacylglycerol (DGDG), which are components of the thylakoid membrane in chloroplasts, were produced more under ML than HL, and more on day 8 than day 12 . This pattern may be related to a reduced photosynthetic apparatus under HL or stress conditions, as reported in plants and microalgae [36, 37]. CrCAO transformants showed significantly increased polar lipid content only under ML on day 12 , which may be related to their significant improvement in growth under these conditions (Fig. 3a, b).

Overall, total lipid contents were similar on day 8 under ML and HL, but increased noticeably on day 12 under 


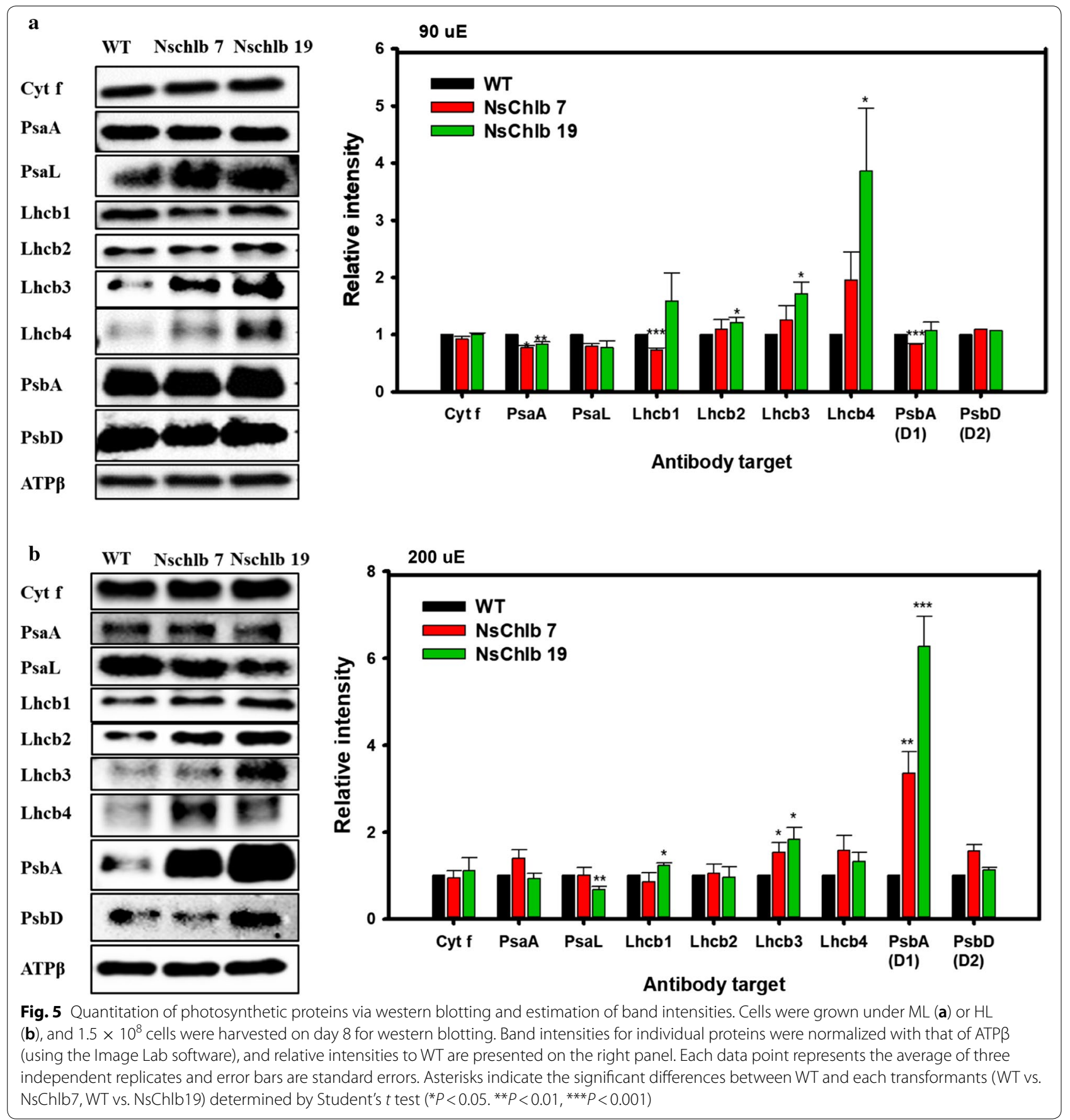

HL compared to ML (Table 2). CrCAO transformants did not show any significant changes in total lipid contents under any conditions. However, they showed a significant increase in biomass under ML on day 12 (Fig. 3b), and we estimated the lipid productivity as shown in Fig. 6. As expected, both transformants showed significantly increased lipid productivities on day 12 with ML (Fig. 6a). Under HL, transformants remained the same as
WT, although NsChlb 19 showed a moderate but significant increase in lipid productivity on day 8 (Fig. 6b).

\section{Discussion}

Nannochloropsis are one of the most important industrial microalgae of which genomic and transcriptomic resources are available [12, 27], and have been subjected to intense strain developments via transcription factor 
Table 2 Lipid contents of WT and NsChlb transformants grown under different light conditions measured by HPLC

\begin{tabular}{|c|c|c|c|c|c|c|}
\hline & Strain & TAG & MAG & MGDG & DGDG & Total \\
\hline \multicolumn{7}{|l|}{$\mathrm{ML}(90 \mu \mathrm{E})$} \\
\hline \multirow[t]{3}{*}{ Day 8} & WT & $3.90 \pm 0.14$ & n.d. & $7.77 \pm 0.13$ & $2.33 \pm 0.05$ & $14.00 \pm 0.13$ \\
\hline & NsChlb 7 & $3.57 \pm 0.27$ & n.d. & $7.64 \pm 0.55$ & $2.56 \pm 0.09 *$ & $13.77 \pm 0.54$ \\
\hline & NsChlb 19 & $4.93 \pm 0.52$ & n.d. & $7.40 \pm 0.21$ & $2.79 \pm 0.19 *$ & $15.12 \pm 0.80$ \\
\hline \multirow[t]{3}{*}{ Day 12} & WT & $3.03 \pm 0.08$ & $2.07 \pm 0.02$ & $5.05 \pm 0.32$ & $2.28 \pm 0.02$ & $14.21 \pm 0.31$ \\
\hline & NsChlb 7 & $2.76 \pm 0.06^{*}$ & $2.01 \pm 0.02$ & $6.30 \pm 0.29^{*}$ & $2.47 \pm 0.03^{* *}$ & $14.37 \pm 0.95$ \\
\hline & NsChlb 19 & $3.06 \pm 0.27$ & $2.01 \pm 0.01$ & $6.12 \pm 0.19^{*}$ & $2.49 \pm 0.05^{* *}$ & $15.67 \pm 0.69$ \\
\hline \multicolumn{7}{|c|}{$\mathrm{HL}(200 \mu \mathrm{E})$} \\
\hline \multirow[t]{3}{*}{ Day 8} & WT & $4.58 \pm 0.62$ & $2.89 \pm 0.03$ & $3.71 \pm 0.06$ & $2.55 \pm 0.02$ & $14.01 \pm 0.81$ \\
\hline & NsChlb 7 & $5.45 \pm 0.56$ & $3.17 \pm 0.13$ & $3.62 \pm 0.02$ & $2.59 \pm 0.06$ & $15.10 \pm 0.70$ \\
\hline & NsChlb 19 & $6.98 \pm 0.81^{*}$ & $2.84 \pm 0.02$ & $3.44 \pm 0.13$ & $2.60 \pm 0.10$ & $15.94 \pm 0.53$ \\
\hline \multirow[t]{3}{*}{ Day 12} & WT & $32.32 \pm 1.41$ & $2.51 \pm 0.02$ & $2.04 \pm 0.05$ & $1.80 \pm 0.04$ & $38.67 \pm 1.33$ \\
\hline & NsChlb 7 & $31.68 \pm 2.14$ & $2.52 \pm 0.07$ & $2.06 \pm 0.10$ & $1.82 \pm 0.07$ & $38.08 \pm 1.92$ \\
\hline & NsChlb 19 & $31.43 \pm 1.77$ & $2.43 \pm 0.03$ & $2.04 \pm 0.04$ & $1.78 \pm 0.02$ & $37.67 \pm 1.71$ \\
\hline
\end{tabular}

The data represent the average value with ranges of standard error $(n=3)$. Asterisks indicates the significant differences between WT and each transformants (WT vs. NsChlb7, WT vs. NsChlb19) determined by Student's $t$ test $\left({ }^{*} P<0.05,{ }^{* *} P<0.01,{ }^{* * *} P<0.001\right)$

engineering [38-40] and metabolic engineering [41, 42]. Overall, they show robust growth and high lipid contents $[43,44]$; however, their photosynthetic efficiency has been questioned due to the lack of pyrenoids and leaky carbon concentrating mechanisms [14, 15, 45]. They are also peculiar in that they lack accessory chlorophylls (Chlb or $\mathrm{Chl}$ ), which is rare in photosynthetic eukaryotes [8, 17, 46]. This opens a unique opportunity to test whether $\mathrm{Chl} b$ would be beneficial for photosynthesis and growth, and further for lipid production in Nannochloropsis.

We found that production of $\mathrm{Chl} b$ by introducing heterologous $\mathrm{CrCAO}$ indeed improved photosynthesis and growth, particularly under ML conditions. These improvements are expected to be caused by the effect of $\mathrm{CrCAO}$, as integration sites of transformants were not found in the coding sequences, revealed by RESDAPCR (Additional file 4: Figure S3). During the process of introducing heterologous proteins into the chloroplast of Nannochloropsis, we learned that the transit peptide was not sufficient for chloroplast localization, because the chloroplast is surrounded by another pair of membranes (forming cER) in heterokonts including Nannochloropsis and diatoms, originating from the secondary endosymbiosis of a red algal ancestor [15, 21-23]. In our earlier attempt to express $\mathrm{CrCAO}$ without any modification, we failed to obtain any transformants that produced $\mathrm{Chl} b$. However, we successfully introduced $\mathrm{CrCAO}$ into the chloroplast by fusing a signal-recognition sequence and transit peptide from a chloroplast-localized protein called GCSL, resulting in the production of active Chl $b$ in Nannochloropsis. The production of $\mathrm{Chl} b$ and the delivery of a heterologous protein into the chloroplast have not been reported in Nannochloropsis except for the cases of marker proteins such as GFP [47].

CrCAO transformants showed improved photosynthetic efficiencies and changed amounts of antennal and photosystem proteins, consistent with functions of $\mathrm{Chl} b$ and $\mathrm{CAO}$ in other photosynthetic organisms. Even though the amount of Chlb synthesized in NsChlb transformants was low compared to other photosynthetic organisms, Chl $b$ played significant roles in photosynthesis. The importance of Chlb is not limited to its function as an accessory chlorophyll. Both $\mathrm{Chl} b$ and its biosynthetic enzyme CAO play important roles in the proper assembly of antennal complexes, in addition to the accessory functions of $\mathrm{Chl} b$ in $\mathrm{LHC}$, contributing to photosynthetic efficiency and growth in plants and green algae, particularly under ML conditions [5, 6, 33]. Lack of Chlb or mutations in CAO result in not only defective photosynthesis but also poor growth-related phenotypes including leaf senescence and stress sensitivity [48]. It would be worthwhile to analyze these beneficial phenotypes in our CrCAO transformants.

A detailed assessment of the photosynthetic parameters and proteins in $\mathrm{CrCAO}$ transformants allowed us to elucidate the mechanisms of the beneficial effects of heterologous expression of $\mathrm{CrCAO}$. We found that the transformants showed increased efficiency of PSII [Y(II)] and relative electron transfer rate (rETR), suggesting enhanced photosynthetic efficiency of PSII. We observed variable increases in the PSII antenna and core components, but not in those of PSI. In particular, Lhcb4 (or CP29, a minor monomeric antennal component) was 

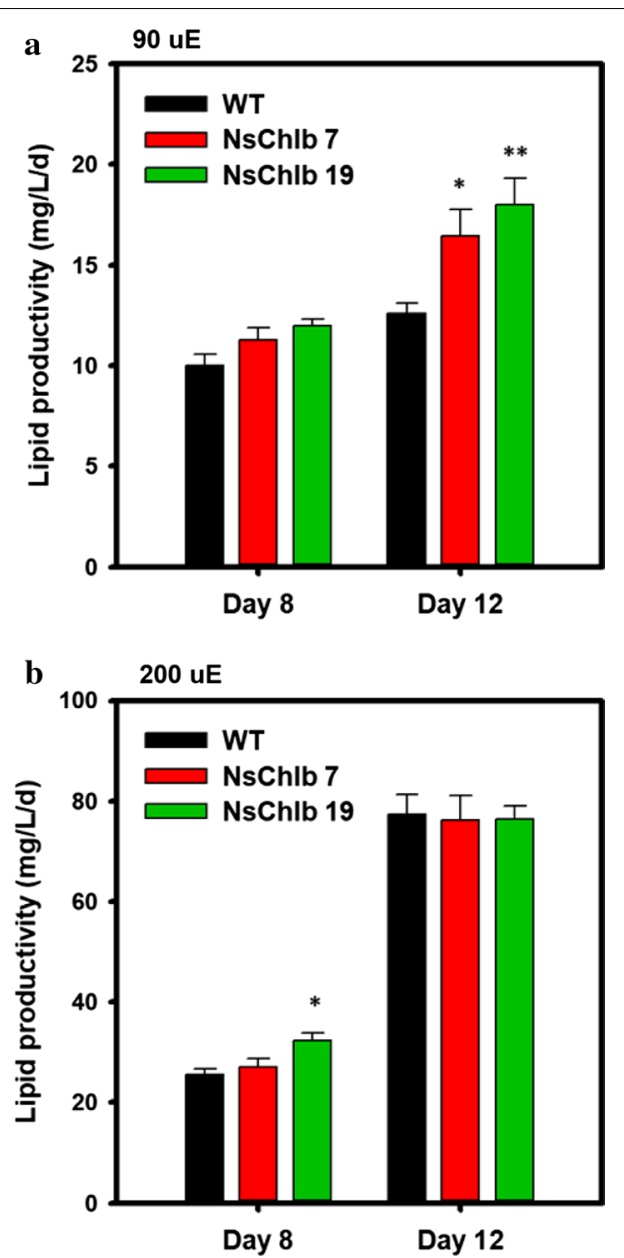

Fig. 6 Total lipid productivities of WT and NsChlb transformants. The total lipid productivity was calculated from the biomass productivity and lipid contents divided by the cultivation period in days. Cells were cultivated under $\mathrm{ML}\left(90 \mu \mathrm{mol}\right.$ photons $\left./ \mathrm{m}^{2} / \mathrm{s}\right)(\mathbf{a})$ and $\mathrm{HL}$ (200 $\mu \mathrm{mol}$ photons $/ \mathrm{m}^{2} / \mathrm{s}$ ) (b) at $25^{\circ} \mathrm{C}, 120 \mathrm{rpm}$ and supplying 0.5 vvm of $2 \% \mathrm{CO}_{2}$. Asterisks indicate the significant differences between WT and each transformants (WT vs. NsChlb7, WT vs. NsChlb19) determined by Student's $t$ test $\left({ }^{*} P<0.05,{ }^{* *} P<0.01,{ }^{* * *} P<0.001, n=3\right.$ )

greatly increased in transformants under ML, which is known to be regulated and stabilized by CAO in plants [5, 33]. Thylakoid membrane lipids including MGDG and DGDG were also increased in transformants under ML, consistent with improved photosynthesis. These galactolipids have also been associated with chloroplast and cell division in plants $[49,50]$. In the case of D1 protein, we noted that the transformants cultivated under HL showed 3.4 and 6.3-fold increase in the amount of D1 while no significant changes were observed under ML. It has been reported that D1 shows rapid turnover under high light conditions, and more susceptible to photo-inhibition than other photosynthetic proteins [51,
52]. Hence, we assume that $\mathrm{Chl} b$ may have protected the D1 protein from degradation under HL, as similar functions have been reported for $\mathrm{Chl} a$ and $\mathrm{Zn}$-pheophytin in plants [52]. However, there should be other unknown reasons for the D1-related functions of $\mathrm{Chl} b$, since the dimeric D2 was not affected in our transformants. This requires more studies, since it is the first time to produce Chlb in Nannochloropsis.

In addition, NPQ was not affected by the expression of CrCAO, suggesting that the novel Chl $b$ does not influence photoprotection. We also observed a moderate but significant decrease in antennal and core proteins, the significance of which is unknown.

Another important improvement in CrCAO transformants was increased biomass and lipid productivity. The improved photosynthetic efficiency apparently increased growth of transformants, resulting in increased biomass especially under ML conditions. This is expected to be effective for outdoor cultivation, as the intensity of the sun varies in time, season, region, and weather, where $\mathrm{Chl} b$ expressing mutants will have better chance for photosynthesis during any time with low intensity light. Indeed, there have been numerous researches on the importance of diffuse radiation compared to direct radiation on photosynthesis in plants [53, 54]. Even though we did not achieve increased lipid contents, this opens the opportunity of exploiting heterologous expression of CAO in industrial production of biofuels and biomaterials in Nannochloropsis. Improved photosynthesis is critical for successful production of materials from microalgae, because it provides fixed organic carbons and energy for all downstream metabolic processes [55, 56]. There have been numerous attempts to improve the metabolic processes per se, but with limited success [57-60]. Metabolic and/or genetic engineering should accompany photosynthetic improvements to support biosynthesis of materials. Our strategy of improving photosynthesis by heterologous production of $\mathrm{Chl} b$ provided an excellent proof of concept for industrial production of biomaterials. It should also be noted that our vector constructed for introducing proteins into the chloroplast in Nannochloropsis is a useful tool for chloroplast engineering in heterokonts.

\section{Conclusion}

In the present study, we synthesized the chlorophyll $b$ in Nannochloropsis salina for the first time by expressing $\mathrm{CrCAO}$ from $C$. reinhardtii. The catalytic region of $\mathrm{CrCAO}$ was sufficient to produce $\mathrm{Chl} b$ in $N$. salina with proper localization lead by signal and transit peptides retrieved from endogenous GCSL sequence. The $\mathrm{Chl} b$ producing transformants showed increased photosynthetic efficiency along with higher amount of LHCs 
related proteins. Moreover, the lipid productivity of the transformants were higher than WT by up to $43 \%$, where the difference was more significant under lower light conditions. These findings revealed positive effects of $\mathrm{Chl} b$ on photosynthesis and growth in a Chlb-less organism, which can be readily employed in the production of biomass and biofuels.

\section{Methods}

\section{Microalgal strains and maintenance conditions}

The algal strains Nannochloropsis salina CCMP 1776 and Chlamydomonas reinhardtii CC-124 were obtained from NCMA (National Center for Marine Algae and Microbiota) and Chlamydomonas Resource Center, respectively. For maintenance of each strain, $N$. salina and $C$. reinhardtii were monthly subcultured on modified $\mathrm{F} 2 \mathrm{~N}$ [15 g/L sea salt, $30 \mathrm{mg} / \mathrm{L} \mathrm{NaH} \mathrm{PO}_{4} \cdot 2 \mathrm{H}_{2} \mathrm{O}, 427.5 \mathrm{mg} / \mathrm{L}$ $\mathrm{NaNO}_{3}, 10 \mathrm{mM}$ Tris- $\mathrm{HCl}$ (pH 7.6), $5 \mathrm{~mL} / \mathrm{L}$ trace metal mixture $\left(3.15 \mathrm{~g} / \mathrm{L} \mathrm{FeCl}_{3} \cdot 6 \mathrm{H}_{2} \mathrm{O}, 4.36 \mathrm{~g} / \mathrm{L} \mathrm{Na}_{2}\right.$ EDTA $2 \mathrm{H}_{2} \mathrm{O}$, $10 \mathrm{mg} / \mathrm{L} \mathrm{CoCl}_{2} \cdot 6 \mathrm{H}_{2} \mathrm{O}, 180 \mathrm{mg} / \mathrm{L} \mathrm{MnCl}{ }_{2} \cdot 4 \mathrm{H}_{2} \mathrm{O}, 22 \mathrm{mg} / \mathrm{L}$ $\mathrm{ZnSO}_{4} \cdot 7 \mathrm{H}_{2} \mathrm{O}, \quad 9.8 \mathrm{mg} / \mathrm{L} \quad \mathrm{CuSO}_{4} \cdot 5 \mathrm{H}_{2} \mathrm{O}, \quad 6.3 \mathrm{mg} / \mathrm{L}$ $\left.\mathrm{Na}_{2} \mathrm{MoO}_{4} \cdot 2 \mathrm{H}_{2} \mathrm{O}\right)$, and $2.5 \mathrm{~mL} / \mathrm{L}$ vitamin stock $(1 \mathrm{mg} / \mathrm{L}$ vitamin B12, $1 \mathrm{mg} / \mathrm{L}$ Biotin, $200 \mathrm{mg} / \mathrm{L}$ thiamine $\cdot \mathrm{HCl})$ ] agar plates and TAP $\left(2.42 \mathrm{~g} / \mathrm{L}\right.$ Tris, $0.375 \mathrm{~g} / \mathrm{L} \mathrm{NH}_{4} \mathrm{Cl}$, $0.1 \mathrm{~g} / \mathrm{L} \mathrm{MgSO}{ }_{4} \cdot 7 \mathrm{H}_{2} \mathrm{O}, 0.05 \mathrm{~g} / \mathrm{L} \mathrm{CaCl}{ }_{2} \cdot 2 \mathrm{H}_{2} \mathrm{O}, 0.0108 \mathrm{~g} / \mathrm{L}$ $\mathrm{K}_{2} \mathrm{HPO}_{4}, 0.0054 \mathrm{~g} / \mathrm{L} \quad \mathrm{KH}_{2} \mathrm{PO}_{4}, 1 \mathrm{~mL} / \mathrm{L}$ glacial acetic acid, and $1 \mathrm{~mL} / \mathrm{L}$ Hutner's trace elements $(50 \mathrm{~g} / \mathrm{L}$ $\mathrm{Na}_{2}$ EDTA. $2 \mathrm{H}_{2} \mathrm{O}, 22 \mathrm{~g} / \mathrm{L} \mathrm{ZnSO} \cdot 7 \mathrm{H}_{2} \mathrm{O}, 11.4 \mathrm{~g} / \mathrm{L} \mathrm{H}_{3} \mathrm{BO}_{3}$, $5.06 \mathrm{~g} / \mathrm{L} \mathrm{MnCl}_{2} \cdot 4 \mathrm{H}_{2} \mathrm{O}, 1.61 \mathrm{~g} / \mathrm{L} \mathrm{CoCl}{ }_{2} \cdot 6 \mathrm{H}_{2} \mathrm{O}, 1.57 \mathrm{~g} / \mathrm{L}$ $\mathrm{CuSO}_{4} \cdot 5 \mathrm{H}_{2} \mathrm{O}, \quad 1.10 \mathrm{~g} / \mathrm{L} \quad\left(\mathrm{NH}_{4}\right) 6 \mathrm{Mo}_{7} \mathrm{O}_{24} \cdot 7 \mathrm{H}_{2} \mathrm{O}$, and $4.99 \mathrm{~g} / \mathrm{L} \mathrm{FeSO}_{4} \cdot 7 \mathrm{H}_{2} \mathrm{O}$ ) agar plates at $25{ }^{\circ} \mathrm{C}$ under continuous illumination of $100 \mu \mathrm{mol} / \mathrm{m}^{2} / \mathrm{s}$.

\section{Vector construction}

The total RNA of C. reinhardtii was extracted at the midexponential phase from $200 \mathrm{mg}$ cell by using an RNeasy Plant mini kit (Qiagen, USA), followed by additional treatment with a DNA-free DNase kit (AMBION, USA) to eliminate any DNA remaining in the product. The RNA was then used as a template to produce cDNA by reverse transcription with Superscript ${ }^{\mathrm{TM}}$ III Reverse Transcriptase (Invitrogen, USA) and an oligo $(\mathrm{dT})_{20}$ primer (Invitrogen, USA). The coding sequence of $\mathrm{CrCAO}$ gene (GenBank accession: XM_001690123.1) was amplified through polymerase chain reaction from the cDNA with CA_1/CA_2 and CA_3/CA_4 primers (Additional file 2: Table S1).

The signal and transit sequences ligated at the $\mathrm{N}$-terminus of the $C r C A O$ were predicted by SignalP $[61,62]$ and ChloroP [63] from the GCSL gene of N. salina. These signal and transit sequences were artificially synthesized in the form of CA1 and BK1 primers, each harboring half of the full leader sequence. The backbone of pNsChlb was amplified from a pNssfCherry vector from our previous study [64] using primers BK1 and BK2 and it contained the TUB promoter/terminator set for the expression of $\mathrm{CrCAO}$ gene. The selection marker Shble was also harbored in the backbone sequence regulated by the UEP promoter/terminator set. The PCR products were assembled altogether into the pNsChlb vector by the Gibson assembly technique [65].

\section{Transformation through electroporation}

For the transformation of N. salina, we performed electroporation based on a previously published report with slight modifications. Cells were grown for 4 days under continuous illumination $\left(120 \mu \mathrm{mol} / \mathrm{m}^{2} / \mathrm{s}\right)$ to the midexponential phase for harvesting. The harvested cells were then concentrated to $5 \times 10^{9}$ cells $/ \mathrm{mL}$ after washing three times with $375 \mathrm{mM}$ sorbitol to eliminate any salts left in the cell. For transformation with an ECM 850 square Wave Electroporation System (Bio-Rad, USA), $50 \mu \mathrm{L}$ of concentrated cells was placed in $0.2-\mathrm{cm}$ gap cuvettes (BTX, USA) with $2 \mu \mathrm{g}$ of linearized vector DNA. The electroporation was conducted under the following conditions: $2400 \mathrm{~V}$ voltage, $100 \mu$ s pulse length, and 50 successive pulses at an interval of $500 \mathrm{~ms}$. Electroporated cells were recovered in modified F2 N media for $15 \mathrm{~h}$ at $25{ }^{\circ} \mathrm{C}$ under a dark condition. Transformed cells were spread on F2 N agar plates containing $2.5 \mu \mathrm{g} / \mathrm{mL}$ Zeocin (Invitrogen, USA) for selection after 4 weeks.

\section{Genomic PCR and RESDA-PCR}

The genomic DNAs of wild-type and pNsChlb transformants were extracted with Instagene Matrix (Bio-Rad, USA) by slightly modulating the manufacturer's guide manual for bacteria. Cells picked from the agar plate were resuspended in $1 \mathrm{~mL}$ of autoclaved water and centrifuged at 13,000 rpm for $1 \mathrm{~min}$. After removing the supernatant, $200 \mu \mathrm{L}$ of Instagene matrix was added into the pellet and incubated at $56^{\circ} \mathrm{C}$ for $10 \mathrm{~min}$, followed by 8 -min incubation at $99{ }^{\circ} \mathrm{C}$. The supernatant of the mixture was then collected by centrifugation and was used as a template for genomic PCR and RESDA-PCR. For genomic PCR, S1/S2 and SR1/SR2 sets of primers were used to detect the shble and 18 srDNA, respectively.

RESDA-PCR was performed following protocols described by Kang et al. [64] except for the primers. For the first amplification step, degenerate primer DegTaqI and RE1 were used, where Q0 and RE2 primers were used for the second amplification step.

\section{Western blot analysis}

A Western blotting analysis was conducted to confirm successful expression of Chlorophyll $a$ Oxygenase in transformants and to examine any changes in the level of 
LHC-relevant proteins during cultivation. $1.5 \times 10^{8}$ cells were harvested on the 8th day from inoculation and were mixed thoroughly with $100 \mu \mathrm{L}$ of $1.5 \times$ modified Laemmli buffer (pH 7.6, $62.5 \mathrm{mM}$ Tris- $\mathrm{HCl}, 25 \%$ glycerol, $5 \% \beta$-mercaptoethanol, 7\% sodium dodecyl sulfate (SDS), and $0.02 \%$ bromophenol blue) [66]. The mixture was then incubated at $99^{\circ} \mathrm{C}$ for $7 \mathrm{~min}$ followed by centrifugation at $13,000 \mathrm{rpm}$ at $4{ }^{\circ} \mathrm{C}$. After centrifugation, the supernatants were collected and subjected to electrophoresis using Mini-PROTEAN ${ }^{\circledR}$ Tetra Vertical Eletrophoresis Cell for Mini Precast Gels (Bio-rad, USA) along with Any kD Mini-PROTEAN ${ }^{\circledR}$ TGX Stain-Free Gels (Bio-rad, USA) in $1 \times$ TGX buffer. The resolved proteins were blotted onto polyvinylidene difluoride (PVDF) membranes using Trans-Blot ${ }^{\circledR}$ Turbo $^{\text {TM }}$ System (Bio-rad, USA). After blocking with phosphate buffer saline (PBS) containing $5 \%$ skim milk and $0.1 \%$ Tween 20 , the transferred membranes were immunoblotted with primary and secondary antibodies sequentially. For primary antibodies, antiFLAG-tag antibody (Cell Signaling Technology, USA) was used at a 1:1000 dilution rate to detect Flag-tag proteins at the C-terminal of transformants and anti-ATP $\beta$ synthase antibody (Agrisera, Sweden) at a 1:5000 dilution rate as a loading control. Additionally, the following light-harvesting complex related proteins were used for this research; Lhcb1 AS01-004 at 1:4000, Lhcb2 AS01003 at 1:10,000, Lhcb3 AS01-002 at 1:2000, Lhcb4 AS06117 at 1:5000, PsaA AS06-176 at 1:1000, PsaL AS06-108 at 1:1000, PsbA AS05-084 at 1:10,000, PsbD AS06-146 at 1:5000, and Cyt f AS06-119 at 1:2000 (Agrisera, Sweden). For secondary antibody, anti-rabbit IgG-horseradish peroxidase (HRP) conjugated antibody (Cell Signaling Technology, USA) was used at a 1:1000 dilution for all types of primary antibodies. Protein bands were visualized with a ChemiDoc system (Bio-Rad, USA) after treating the membranes with enhanced chemiluminescence (ECL) reagents (Bio-Rad, USA).

\section{Chlorophyll extraction and HPLC analysis}

We harvested $N$. salina cells on the 8th and 12th days during cultivation and freeze-dried them for the analyses of chlorophylls and lipids. For sample preparation, lyophilized cells each of $5 \mathrm{mg}$ were prepared in $2-\mathrm{mL}$ tubes (Bertin Technologies, USA) with 0.1 -and $0.5-\mathrm{mm}$ diameter zirconia/silica beads. After adding $1.1 \mathrm{~mL}$ of HPLC-grade acetone (Sigma-Aldrich, USA) in the tubes, samples were subjected to bead beating at $6000 \mathrm{rpm}$ for 40 s using a bead beater (Percellys 24, Bertin Technologies, USA). In total 10 times of bead beating was applied for each samples, and to avoid pigment degradation by heat, cells were cooled down in ice after each cycles. After filtering the supernatant with a $0.20-\mu \mathrm{m}$ RC-membrane syringe filter (Sartorius Stedim Biotech, Germany), chlorophylls were analyzed by high performance liquid chromatography (HPLC) (Dionex Ultimate 3000, Thermo Scientific, USA) with a UV detector (Ultimate 3000 VWD Variable Wavelength Detector, Thermo Scientific, USA)

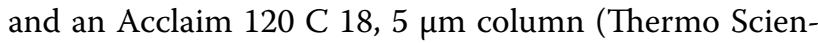
tific, USA). For the mobile phase, a (A) methanol- $0.5 \mathrm{M}$ ammonium acetate mixture $(80: 20, \mathrm{v} / \mathrm{v})$ and a (B) methanol-acetone mixture $(70: 30, \mathrm{v} / \mathrm{v})$ were flowed at a rate of $0.8 \mathrm{~mL} / \mathrm{min}$. The ratio of solvents (A) and (B) flowing into the column was gradually changed with the elapse of time.

\section{Photoautotrophic cultivation}

Wild-type and NsChlb transformants were cultivated under high light $\left(200 \mu \mathrm{mol} / \mathrm{m}^{2} / \mathrm{s}\right)$ and mid light $(90 \mu \mathrm{mol} /$ $\mathrm{m}^{2} / \mathrm{s}$ ) in a F2 $\mathrm{N}$ medium at $25^{\circ} \mathrm{C}$ with $120 \mathrm{rpm}$ agitation. Each baffled flask contained $200 \mathrm{~mL}$ of cells, and a carbon source was directly supplied into the flasks in the form of $2 \% \mathrm{CO}_{2}$ at $0.5 \mathrm{vvm}$. The growth was determined by optical density, cell density, and dry cell weight (DCW). For each analysis, an automated cell counter $\left(\right.$ Cellometer $^{\circledR}$ Auto X4, Nexcelom, USA), UV-VIS spectrophotometer (UV-1800, Shimadzu, Japan), and GF/C filter paper (Whatman, USA) were used. The DCW was calculated by weighing the filter paper before and after filtering cells, which went through a delicate washing and drying procedure.

\section{Total lipid extraction and HPLC analysis}

For total lipid extraction, $10 \mathrm{~mL}$ of chloroform-methanol mixture $(2: 1, \mathrm{v} / \mathrm{v})$ was added to $20 \mathrm{mg}$ of lyophilized cells and then sonicated for $1 \mathrm{~h}$. To remove proteins and carbohydrates, $2.5 \mathrm{~mL}$ of deionized water was added and then vigorously mixed for $10 \mathrm{~min}$, followed by centrifugation at $4000 \mathrm{rpm}$ to separate the organic phase from the inorganic phase. We only collected the organic phase at the lower layer and filtered it through a $0.20-\mu \mathrm{m}$ RCmembrane syringe filter (Satorius Stedim Biotech, Germany) to remove any impurities. After filtration, total lipids were analyzed by a high performance liquid chromatography (HPLC) (Agilent 1260, Agilent, USA) with an ELSD detector (Agilent 1260 ELSD, Agilent, USA) and a Chromolith Performance-Si $(100 \times 4.6 \mathrm{~mm}$ I.D) column (Merck Millipore, USA). A modified method for the gradient system was used based on previous reports [67].

\section{Photosynthetic activity measurement}

The absorption spectra of wild-type and NsChlb transformantswere simply measured from 400 to $800 \mathrm{~nm}$ using a UV-VIS spectrophotometer (UV-1800, Shimadzu, Japan).

The fluorescence yield and light-response curves were measured in vivo with Multi-color-PAM (Heinz-Walz, 
Germany) as previously described [68, 69]. Cultured cells were dark adapted for 20 min before analysis for all the reaction centers to be opened. The photosynthetic parameters including relative electron transport rate (rel. ETR), and effective quantum yield of PS II (Y(II)) were measured with increasing light intensities of $440 \mathrm{~nm}$ LED light with a step length of $3 \mathrm{~min}$.

\section{Immunogold labeling and transmission electron microscopy}

In order to examine the localization of the expressed CrCAO protein, immunogold labeling was used with transmission electron microscopy. Harvested cells of WT and NsChlb19 transformant were washed with PBS buffer before fixation in ice for $20 \mathrm{~min}$ with fixation agent (4\% paraformaldehyde with $0.1 \%$ glutaraldehyde). After washing three times with PBS buffer, cells were harvested in PBS solution containing $1 \%$ gelatin. Then, washing step after centrifugation for $2 \mathrm{~min}$ at $3000 \mathrm{rpm}$ was repeated, increasing the content of gelatin in PBS from $2.5 \%, 7.5 \%$ and to $10 \%$. For the steps with $2.5 \%$ gelatin and $7.5 \%$ gelatin, cells were incubated at $37{ }^{\circ} \mathrm{C}$ for $10 \mathrm{~min}$. In the last step with $10 \%$ gelatin, cells were incubated in ice for $20 \mathrm{~min}$. The samples were then sliced into $0.5-1 \mathrm{~mm}$, which were supplemented with $2.3 \mathrm{M}$ sucrose at $4{ }^{\circ} \mathrm{C}$ for overnight. After slicing the sample into sections, primary antibody of anti-FLAG-tag antibody (Cell Signaling Technology, USA) was used, followed by secondary goldlabeled anti-rabbit IgG antibody (Abcam, UK). Transmission microscopy image was taken with Tecnai $\mathrm{G}^{2}$ spirit TWIN transmission microscope (FEI, USA).

\section{Additional files}

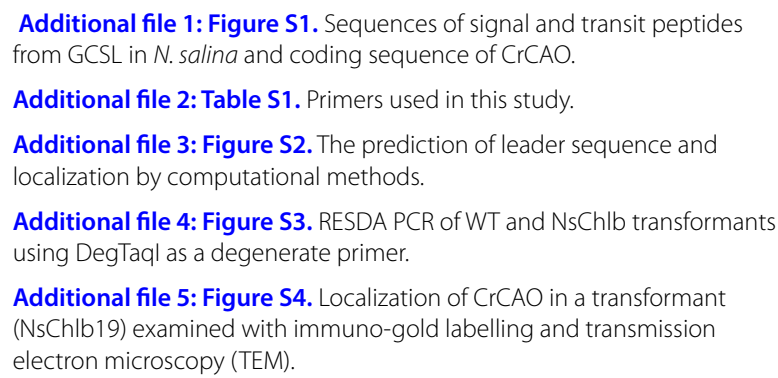

\section{Abbreviations}

DCW: dry cell weight; FAME: fatty acid methyl ester; Chl: chlorophyll; CAO: chlorophyllide $a$ oxygenase; cER: chloroplast endoplasmic reticulum; LHCS: light-harvesting complexes; GCSL: Glycine Cleavage System L protein; CTP: chloroplast transit peptide; ML: medium light; HL: high light; MAG: monoacylglycerol; MGDG: monogalactosyldiacylglycerol; DGDG: digalactosyldiacylglycerol; rETR: relative electron-transfer rate; NPQ: non-photochemical quenching; TAG: triacylglycerol.

\section{Acknowledgements}

We thank the Advanced Biomass R\&D Center (ABC) of the Global Frontier Project, funded by the Ministry of Science and ICT (ABC-2010-0029728, 20110031343 and 2011-0031350).

\section{Authors' contributions}

HGK, YKC, and B-rJ designed the overall experiment, interpreted the data, and wrote the manuscript. HGK conducted transformation and cultivation of NsChlb 7, 19 strains. HGK, NKK, and JSJ measured the photosynthetic parameters and lipid yields and analyzed the chlorophyll contents. HGK and SES worked on the immunoblotting of target proteins. All the authors read and approved the final manuscript.

\section{Funding}

This work was supported by the Advanced Biomass R\&D Center (ABC) of the Global Frontier Project, funded by the Ministry of Science and ICT (ABC-20100029728, 2011-0031343 and 2011-0031350).

\section{Availability of data and materials}

All data generated or analyzed during this study are included in this published article.

\section{Ethics approval and consent to participate}

Not applicable.

\section{Consent for publication}

Not applicable.

\section{Competing interests}

The authors declare that they have no competing interests.

\section{Author details}

1 Advanced Biomass R\&D Center, 291 Daehak-ro, Yuseong-gu, Daejeon 34141, Republic of Korea. ${ }^{2}$ Department of Chemical and Biomolecular Engineering, KAIST, 291 Daehak-ro, Yuseong-gu, Daejeon 34141, Republic of Korea. ${ }^{3}$ Present Address: Carl R. Woese Institute for Genomic Biology, University of Illinois at Urbana-Champaign, Urbana, IL, USA. ${ }^{4}$ Present Address: LG Chem, 188 Munji-ro, Yuseong-gu, Daejeon 34122, Republic of Korea.

Received: 15 January 2019 Accepted: 4 May 2019

Published online: 14 May 2019

\section{References}

1. Mackinder $\mathrm{LCM}$. The Chlamydomonas $\mathrm{CO}_{2}$-concentrating mechanism and its potential for engineering photosynthesis in plants. New Phytol. 2018;217:54-61.

2. Chen M. Chlorophyll modifications and their spectral extension in oxygenic photosynthesis. Annu Rev Biochem. 2014;83:317-40.

3. Vasil'ev S, Bruce D. Optimization and evolution of light harvesting in photosynthesis: the role of antenna chlorophyll conserved between photosystem II and photosystem I. Plant Cell. 2004;16:3059-68.

4. Björn LO, Papageorgiou GC, Blankenship RE, Govindjee. A viewpoint: why chlorophyll a? Photosynth Res. 2009;99:85-98.

5. Voitsekhovskaja OV, Tyutereva EV. Chlorophyll b in angiosperms: functions in photosynthesis, signaling and ontogenetic regulation. J Plant Physiol. 2015;189:51-64.

6. Nick S, Meurer J, Soll J, Ankele E. Nucleus-encoded light-harvesting chlorophyll a/b proteins are imported normally into chlorophyll b-free chloroplasts of Arabidopsis. Mol Plant. 2013;6:860-71.

7. Green BR. After the primary endosymbiosis: an update on the chromalveolate hypothesis and the origins of algae with Chl c. Photosynth Res. 2011;107:103-15

8. Basso S, Simionato D, Gerotto C, Segalla A, Giacometti GM, Morosinotto T. Characterization of the photosynthetic apparatus of the Eustigmatophycean Nannochloropsis gaditana: evidence of convergent evolution in the supramolecular organization of photosystem I. Biochem Biophys Acta. 2014;1837:306-14.

9. Kuczynska P, Jemiola-Rzeminska M, Strzalka K. Photosynthetic pigments in diatoms. Mar Drugs. 2015;13:5847-81. 
10. Ma XN, Liu J, Liu B, Chen TP, Yang B, Chen F. Physiological and biochemical changes reveal stress-associated photosynthetic carbon partitioning into triacylglycerol in the oleaginous marine alga Nannochloropsis oculata. Algal Res. 2016;16:28-35.

11. Banerjee A, Maiti SK, Guria C, Banerjee C. Metabolic pathways for lipid synthesis under nitrogen stress in Chlamydomonas and Nannochloropsis. Biotechnol Lett. 2017;39:1-11.

12. Radakovits R, Jinkerson RE, Fuerstenberg SI, Tae H, Settlage RE, Boore JL, et al. Draft genome sequence and genetic transformation of the oleaginous alga Nannochloropsis gaditana. Nat Commun. 2012;3:686.

13. Han D, Jia J, Li J, Sommerfeld M, Xu J, Hu Q. Metabolic remodeling of membrane glycerolipids in the microalga Nannochloropsis oceanica under nitrogen deprivation. Front Mar Sci. 2017:4:1-15.

14. Gee CW, Niyogi KK. The carbonic anhydrase CAH1 is an essential component of the carbon-concentrating mechanism in Nannochloropsis oceanica. Proc Natl Acad Sci USA. 2017;114:4537-42.

15. Mackinder LC, Meyer MT, Mettler-Altmann T, Chen VK, Mitchell MC, Caspari $\mathrm{O}$, et al. A repeat protein links Rubisco to form the eukaryotic carbonconcentrating organelle. Proc Natl Acad Sci USA. 2016;113:5958-63.

16. Xu M, Kinoshita Y, Matsubara S, Tamiaki H. Synthesis of chlorophyllc derivatives by modifying natural chlorophyll-a. Photosynth Res. 2016;127:335-45.

17. Kunugi M, Takabayashi A, Tanaka A. Evolutionary changes in chlorophyllide a oxygenase $(\mathrm{CAO})$ structure contribute to the acquisition of a new light-harvesting complex in Micromonas. J Biol Chem. 2013;288:19330-41.

18. Tanaka A, Ito H, Tanaka R, Tanaka NK, Yoshida K, Okada K. Chlorophyll a oxygenase (CAO) is involved in chlorophyll b formation from chlorophyll a. Proc Natl Acad Sci USA. 1998;95:12719-23.

19. Biswal AK, Pattanayak GK, Pandey SS, Leelavathi S, Reddy VS, Govindjee, et al. Light intensity-dependent modulation of chlorophyll b biosynthesis and photosynthesis by overexpression of chlorophyllide a oxygenase in tobacco. Plant Physiol. 2012;159:433-49.

20. Yamasato A, Tanaka R, Tanaka A. Loss of the N-terminal domain of chlorophyllide $a$ oxygenase induces photodamage during greening of Arabidopsis seedlings. BMC Plant Biol. 2008;8:64.

21. Nagata N, Satoh S, Tanaka R, Tanaka A. Domain structures of chlorophyllide a oxygenase of green plants and Prochlorothrix hollandica in relation to catalytic functions. Planta. 2004;218:1019-25.

22. Hirashima M, Satoh S, Tanaka R, Tanaka A. Pigment shuffling in antenna systems achieved by expressing prokaryotic chlorophyllide $a$ oxygenase in Arabidopsis. J Biol Chem. 2006;281:15385-93.

23. Facchinelli F, Weber APM. The metabolite transporters of the plastid envelope: an update. Front Plant Sci. 2011;2:50.

24. Gruber A, Rocap G, Kroth PG, Armbrust EV, Mock T. Plastid proteome prediction for diatoms and other algae with secondary plastids of the red lineage. Plant J Cell Mol Biol. 2015;81:519-28.

25. Sunaga Y, Maeda Y, Yabuuchi T, Muto M, Yoshino T, Tanaka T. Chloroplasttargeting protein expression in the oleaginous diatom Fistulifera solaris JPCC DA0580 toward metabolic engineering. J Biosci Bioeng. 2015;119:28-34.

26. Polle JE, Benemann JR, Tanaka A, Melis A. Photosynthetic apparatus organization and function in the wild type and a chlorophyll $b$-less mutant of Chlamydomonas reinhardtii. Dependence on carbon source. Planta. 2000:211:335-44.

27. Corteggiani Carpinelli E, Telatin A, Vitulo N, Forcato C, D'Angelo M, Schiavon R, et al. Chromosome scale genome assembly and transcriptome profiling of Nannochloropsis gaditana in nitrogen depletion. Mol Plant. 2014;7:323-35.

28. Petersen TN, Brunak S, von Heijne G, Nielsen H. SignalP 4.0: discriminating signal peptides from transmembrane regions. Nat Methods. 2011:8:785-6

29. Emanuelsson O, Nielsen H, Von Heijne G. ChloroP, a neural network-based method for predicting chloroplast transit peptides and their cleavage sites. Protein Sci. 1999;8:978-84.

30. Gschloessl B, Guermeur Y, Cock JM. HECTAR: a method to predict subcellular targeting in heterokonts. BMC Bioinformatics. 2008;9:393.
31. Murchie EH, Lawson T. Chlorophyll fluorescence analysis: a guide to good practice and understanding some new applications. J Exp Bot. 2013;64:3983-98

32. Tanaka A, Melis A. Irradiance-dependent changes in the size and composition of the chlorophyll a-b light-harvesting complex in the green alga Dunaliella salina. Plant Cell Physiol. 1997;38:17-24.

33. Reinbothe C, Bartsch S, Eggink LL, Hoober JK, Brusslan J, Andrade-Paz R, et al. A role for chlorophyllide a oxygenase in the regulated import and stabilization of light-harvesting chlorophyll a/b proteins. Proc Natl Acad Sci USA. 2006;103:4777-82.

34. Shin W-S, Lee B, Kang NK, Kim Y-U, Jeong W-J, Jeong B et al. Complementation of a mutation in CPSRP43 causing partial truncation of light-harvesting chlorophyll antenna in Chlorella vulgaris. Sci Rep. 2017;7:17929.

35. Eggink LL, Park H, Hoober JK. The role of chlorophyll b in photosynthesis: hypothesis. BMC Plant Biol. 2001;1:2.

36. Hanelt D, Melchersmann B, Wiencke C, Nultsch W. Effects of high light stress on photosynthesis of polar macroalgae in relation to depth distribution. Mar Ecol Prog Ser. 1997;149:255-66.

37. Bhandari R, Sharma PK. High-light-induced changes on photosynthesis, pigments, sugars, lipids and antioxidant enzymes in freshwater (Nostoc spongiaeforme) and marine (Phormidium corium) cyanobacteria. Photochem Photobiol. 2006;82:702-10.

38. Kang NK, Kim EK, Kim YU, Lee B, Jeong WJ, Jeong BR, et al. Increased lipid production by heterologous expression of AtWRI1 transcription factor in Nannochloropsis salina. Biotechnol Biofuels. 2017;10:231.

39. Kang NK, Jeon S, Kwon S, Koh HG, Shin SE, Lee B, et al. Effects of overexpression of a bHLH transcription factor on biomass and lipid production in Nannochloropsis salina. Biotechnol Biofuels. 2015;8:200.

40. Kwon S, Kang NK, Koh HG, Shin SE, Lee B, Jeong BR, et al. Enhancement of biomass and lipid productivity by overexpression of a bZIP transcription factor in Nannochloropsis salina. Biotechnol Bioeng. 2018;115:331-40.

41. Zienkiewicz K, Zienkiewicz A, Poliner E, Du ZY, Vollheyde K, Herrfurth C, et al. Nannochloropsis, a rich source of diacylglycerol acyltransferases for engineering of triacylglycerol content in different hosts. Biotechnol Biofuels. 2017;10:8.

42. Beacham TA, Ali ST. Growth dependent silencing and resetting of DGA1 transgene in Nannochloropsis salina. Algal Res Biomass Biofuels Bioproducts. 2016;14:65-71.

43. Ma XN, Chen TP, Yang B, Liu J, Chen F. Lipid production from Nannochloropsis. Mar Drugs. 2016;14:61.

44. McGowen J, Knoshaug EP, Laurens LML, Dempster TA, Pienkos PT, Wolfrum E, et al. The algae testbed public-private partnership (ATP3) framework; establishment of a national network of testbed sites to support sustainable algae production. Algal Res. 2017;25:168-77.

45. Hanson DT, Collins AM, Jones HD, Roesgen J, Lopez-Nieves S, Timlin $J A$. On-line stable isotope gas exchange reveals an inducible but leaky carbon concentrating mechanism in Nannochloropsis salina. Photosynth Res. 2014;121:311-22.

46. Brown JS. Functional organization of chlorophyll $a$ and carotenoids in the alga, Nannochloropsis salina. Plant Physiol. 1987;83:434-7.

47. Moog D, Stork S, Reislohner S, Grosche C, Maier UG. In vivo localization studies in the stramenopile alga Nannochloropsis oceanica. Protist. 2015;166:161-71.

48. Yang $Y, X u J$, Huang L, Leng $Y$, Dai L, Rao Y, et al. PGL, encoding chlorophyllide a oxygenase 1 , impacts leaf senescence and indirectly affects grain yield and quality in rice. J Exp Bot. 2016;67:1297-310.

49. Dörmann P, Benning C. Galactolipids rule in seed plants. Trends Plant Sci. 2002;7:112-8.

50. Narasimhan R, Wang G, Li M, Roth M, Welti R, Wang X. Differential changes in galactolipid and phospholipid species in soybean leaves and roots under nitrogen deficiency and after nodulation. Phytochemistry. 2013:96:81-91.

51. Kato Y, Sun XW, Zhang LX, Sakamoto W. Cooperative D1 degradation in the photosystem II repair mediated by chloroplastic proteases in Arabidopsis. Plant Physiol. 2012;159:1428-39.

52. Eichacker LA, Helfrich M, Rudiger W, Muller B. Stabilization of chlorophyll a-binding apoproteins P700, CP47, CP43, D2, and D1 by chlorophyll a or Zn-pheophytin a. J Biol Chem. 1996;271:32174-9. 
53. Li T, Heuvelink E, DueckTA, Janse J, Gort G, Marcelis LF. Enhancement of crop photosynthesis by diffuse light: quantifying the contributing factors. Ann Bot. 2014;114:145-56.

54. Farquhar GD, Roderick ML. Atmospheric science. Pinatubo, diffuse light, and the carbon cycle. Science. 2003;299:1997-8.

55. Alboresi A, Perin G, Vitulo N, Diretto G, Block M, Jouhet J, et al. Light remodels lipid biosynthesis in Nannochloropsis gaditana by modulating carbon partitioning between organelles. Plant Physiol. 2016;171:2468-82.

56. Zhao BT, Su YX. Process effect of microalgal-carbon dioxide fixation and biomass production: a review. Renew Sustain Energy Rev. 2014;31:121-32.

57. Wei HH, Shi Y, Ma XN, Pan YF, Hu HH, Li YT, et al. A type-I diacylglycerol acyltransferase modulates triacylglycerol biosynthesis and fatty acid composition in the oleaginous microalga, Nannochloropsis oceanica. Biotechnol Biofuels. 2017;10:174.

58. Nobusawa T, Hori K, Mori H, Kurokawa K, Ohta H. Differently localized lysophosphatidic acid acyltransferases crucial for triacylglycerol biosynthesis in the oleaginous alga Nannochloropsis. Plant J. 2017;90:547-59.

59. Ma XN, Yao LN, Yang B, Lee YK, Chen F, Liu J. RNAi-mediated silencing of a pyruvate dehydrogenase kinase enhances triacylglycerol biosynthesis in the oleaginous marine alga Nannochloropsis salina. Sci Rep. 2017;7:11485.

60. Li DW, Cen SY, Liu YH, Balamurugan S, Zheng XY, Alimujiang A, et al. A type 2 diacylglycerol acyltransferase accelerates the triacylglycerol biosynthesis in heterokont oleaginous microalga Nannochloropsis oceanica. J Biotechnol. 2016;229:65-71.

61. Bendtsen JD, Nielsen H, von Heijne G, Brunak S. Improved prediction of signal peptides: SignalP 3.0. J Mol Biol. 2004;340:783-95.

62. Gruber A, Rocap G, Kroth PG, Armbrust EV, Mock T. Plastid proteome prediction for diatoms and other algae with secondary plastids of the red lineage. Plant J. 2015;81:519-28.
63. Emanuelsson O, Nielsen H, Brunak S, von Heijne G. Predicting subcellular localization of proteins based on their $\mathrm{N}$-terminal amino acid sequence. J Mol Biol. 2000;300:1005-16.

64. Kang NK, Choi G-G, Kim EK, Shin S-E, Jeon S, Park MS, et al. Heterologous overexpression of sfCherry fluorescent protein in Nannochloropsis salina. Biotechnol Rep. 2015;8:10-5.

65. Gibson DG, Young L, Chuang RY, Venter JC, Hutchison CA, Smith HO. Enzymatic assembly of DNA molecules up to several hundred kilobases. Nat Methods. 2009;6:343-U341.

66. Laemmli UK. Cleavage of structural proteins during the assembly of the head of bacteriophage T4. Nature. 1970;227:680-5.

67. Graeve M, Janssen D. Improved separation and quantification of neutral and polar lipid classes by HPLC-ELSD using a monolithic silica phase: application to exceptional marine lipids. J Chromatogr B. 2009;877:1815-9.

68. Schreiber U, Klughammer C. Wavelength-dependent photodamage to Chlorella investigated with a new type of multi-color PAM chlorophyll fluorometer. Photosynth Res. 2013;114:165-77.

69. Schreiber U, Klughammer C, Kolbowski J. Assessment of wavelengthdependent parameters of photosynthetic electron transport with a new type of multi-color PAM chlorophyll fluorometer. Photosynth Res. 2012;113:127-44.

\section{Publisher's Note}

Springer Nature remains neutral with regard to jurisdictional claims in published maps and institutional affiliations.
Ready to submit your research? Choose BMC and benefit from:

- fast, convenient online submission

- thorough peer review by experienced researchers in your field

- rapid publication on acceptance

- support for research data, including large and complex data types

- gold Open Access which fosters wider collaboration and increased citations

- maximum visibility for your research: over $100 \mathrm{M}$ website views per year

At BMC, research is always in progress.

Learn more biomedcentral.com/submissions 